\title{
BioCore
}

International Journal of Pharma Sciences and Scientific Research

\section{Underlying Side Effects of Caffeine}

Muhammad Torequl Islam*

*Department of Pharmacy, Southern University Bangladesh, Mehedibag (Chittagong)-4000, Bangladesh

"Northeast Biotechnology Network (RENORBIO), Postgraduate Program in Pharmaceutical Sciences, Federal University of Piaui (UFPI), Teresina (PI)-64.049-550, Brazil

Corresponding Author: Muhammad Torequl Islam, Department of Pharmacy, Southern University Bangladesh, Mehedibag (Chittagong)-4000, Bangladesh. \& Northeast Biotechnology Network (RENORBIO), Postgraduate Program in Pharmaceutical Sciences, Federal University of Piaui (UFPI), Teresina (PI)-64.049-550, Brazil. Email: mti031124@gmail.com

Citation: Muhammad Torequl Islam (2016),Underlying Side Effects of Caffeine. Int J Pharm Sci \& Scient Res. 2:6, 187-191. DOI: 10.25141/2471-6782-2016-6.0253

Copyright: (C)2016 Muhammad Torequl Islam. This is an open-access article distributed under the terms of the Creative Commons Attribution License, which permits unrestricted use, distribution, and reproduction in any medium, provided the original author and source are credited

Received: December 18, 2016; Accepted: December 21, 2016; Published: December 30, 2016

\section{ABSTRACT}

The popular drink, coffee is in great attention due to its promising pharmacological effects. Caffeine (CFE), the known coffee constituent is mainly known for its prominent psychoactive effect on the central nervous system. It has antioxidant, anti-inflammatory, immunomodulatory, antimicrobial, neuro-, lung-, cardiac-, hepato-, reproductive system protective, antidiabetic, anticancer, bone formation and so forth important biological effects. However, CFE is evident to produce a number of side effects in human and other animals. This writing aims at sketching a current underlying toxicological scenario of CFE in human and other animals. Findings suggest that CFE's toxicological impacts are plugged in its dose as well as age, sex, and pathophysiology of the patients. More precautions are needed during pregnancy, those who are planning to be pregnant, lactating women, children, and adolescents, patients with hepatic and cardiovascular complications. Additionally, CFE has toxicological effects on the reproductive system and birth weight. In conclusion, more researches are appreciated to set safe dosages of CFE in groups of consumer.

Keywords: Caffeine, Psychoactive, Toxicity.

\section{Introduction:}

It is noteworthy that, coffee is a popular drink nowadays, as people throughout the world are starting and finishing their days with cups of coffee. The biological source of coffee is the Coffea arabica (Family- Rubiaceae), cultivated in many countries. Coffee started its journey at least 1200 years ago in Ethiopia, then followed by Yemeni Sufi monasteries in the Middle East and northern Africa, Middle East, Europe, America and so on (Wolf et al., 2008).

Caffeine (1,3,7-trimethyl xanthine) $\left(\mathrm{C}_{8} \mathrm{H}_{10} \mathrm{~N}_{4} \mathrm{O}_{2}\right.$; CFE), the natural alkaloid is the well-known component of coffee. This psychoactive ingredient was isolated in 1820 (Frary et al., 2005) from the coffee beans and now being used in a number of food and drinks.

More than 60 plants of which cocoa beans, kola nuts, tea leaves and coffee beans are the most well-known sources of CFE. Other natural sources of CFE include yerba maté, guarana berries, guayusa, and the yaupon holly. Not only the coffee but also tea, soft and energy drinks, chocolate products, medications (e. g.headache treatments, painkillers, over-the-counter stimulants) and few dietary supplements are the main sources of CFE. Observed
CFE in some marked products are: chocolates (1-120 mg), energy drinks (33-400 mg), carbonated beverages (22-69 mg), alcoholic beverages (3-9 $\mathrm{mg}$ ), fast foods (1-49 $\mathrm{mg}$ ), caffeinated waters (42-125 mg), caffeinated soft drinks (30-48 mg), decaffeinated coffee (1-5 mg), espresso (50-150), tea bag (2-130 mg), brewed/ percolated, decaffeinated (3-12 mg), instant and regular drip (30$330 \mathrm{mg}$ ). Although, CFE has been proven for a number of important biological activities, but it has toxicological impacts also (Ashton, 1987; Islam et al., 2016). This writing aims at sketching only the toxicological status of CFE.

\section{Toxicological effects of caffeine (CFE)}

\subsection{Mechanisms invonved}

In a wakeful state, over time adenosine accumulates in the neuronal synapse, binds and causes activation of the adenosine receptors (especially A1, A2A, A2B, and A3) in CNS neurons and produce a drowsiness effect. Having both water- and lipid-solubility, CFE readily crosses the blood-brain barrier (Fisone et al., 2004) and placenta barrier (Mejia et al., 2014). CFE prevents adenosine 
to bind with its receptors, which causes the relief of drowsiness and restoring of alertness. Additionally, this antagonistic effect of CFE stimulates the medullary vagal, vasomotor, and respiratory centers, leading to an increase in respiratory and heart rates, and constriction of blood vessels. Heart palpitations along with the latter case may cause by the blockade of the A1A receptor. Moreover, this antagonism is capable to promote the release of stimulatory neurotransmitters (e.g. - monoamines and acetylcholine) (Drugbank, 2013). Otherwise, CFE can readily cross the placenta barrier and maintains the same concentration between the fetus and the mother, which may connect its abortion facilitator as well as an impaired fetus grows (Mejia et al., 2014).

During the failure of direct binding to any dopamine receptors, CFE can manipulate the binding activity of dopamine at its receptor in the striatum by binding to adenosine receptors, leading to the formation of GPCR heteromers, specifically the A1-D1 (heterodimer) and A2A-D2 (heterotetramer) forms. The psychostimulatory effect of CFE may be plugged on the latter form. The chronic use of CFE may reduce dopamine release via the stimulation of A1-A2A heterodimer in the axon terminal of glutamate neurons and leads CFE tolerance. CFE antagonizes A2A receptor in the ventrolateral preoptic area and reduces inhibitory neurotransmission, especially gamma-amino butyric acid (GABA) to the tuberomammillary nucleus, a histaminergic projection nucleus, activation of which may promote the arousal effect of it (Bonaventura et al., 2015). CFE, otherwise, through its phosphodiesterase inhibitory potential, augments the intracellular cyclic AMP (cAMP), and activates protein kinase-A (PK-A), downregulates tumor necrosis factoralpha $(\mathrm{TNF}-\alpha)$ and leukotriene synthesis along with a reduction of inflammation and innate immunity. It was also inhibited the enzyme acetylcholinesterase (AChE) (Pohanka, 2014). Inhibition of AChE is associated with an accumulation of acetylcholine in the synaptic cleft and in impeded neurotransmission. Otherwise, an irreversible inhibition of $\mathrm{AChE}$ may lead to muscular paralysis, convulsions, bronchial constriction, and death by asphyxiation.

\section{Known}

CFE at low dose in some peoples is experienced in insomnia (Mayo Clinic Staff, 2012), mild drug dependence (235 mg/ day) - associated with withdrawal symptoms such as sleepiness, headache, irritability, fatigue, augmented in blood pressure (BP) and heart rate, urine volume, depressed mood, reduced contentedness, inability to concentrate, drowsiness, stomach and joint pain (Malenka et al., 2009; APA, 2013). Extensive precautions are recommended during pregnancy with CFE $(>200-300 \mathrm{mg})$ (Mayo Clinic Staff, 2012). Otherwise, excess consumption of CFE may increase in BP and causes vasoconstriction (Mahmud and Feely, 2015), affect gastrointestinal motility and gastric acid secretion (Sherwood and Kell, 2010), bone loss (MedlinePlus, 2013), dehydration (O’Connor, 2009), anxiety and panic disorders (> $300 \mathrm{mg}$ ) (Vilarim et al., 2011), low birth weight (Chen et al., 2014), colorectal cancer (Arab, 2010), intraocular pressure in glaucoma ( $\mathrm{Li}$ et al., 2011), caffeinism (1000-1500 mg/day) and CFE dependency (Iancu et al., 2007). Additionally, nervousness, restlessness, palpitations, fidgeting, excitement, flushing of the face, muscle twitching, a rambling flow of thought and speech, irregular or rapid heartbeats, psychomotor agitation, mania, lapses in judgment, disorientation, disinhibition, hallucinations, psychosis, and rhabdomyolysis are also plugged in CFE overdose (MedlinePlus, 2006; Iancu et al., 2007). Massive overdose can result in death (FDA 2014). The LD50 estimated of CFE in humans is 150 to $200 \mathrm{mg} / \mathrm{kg}$ (approximately 75-100 cups of coffee for a 70 kilogram adult) (Peters, 1967).

\section{Metabolite-mediated:}

CFE is metabolized in the liver by the cytochrome P450 oxidase enzyme system mainly into the three dimethylxanthines: paraxanthine, theobromine and theophylline by $84 \%, 12 \%$ and $4 \%$, respectively. Paraxanthine increases lipolysis, leading to an elevation of glycerol and free fatty acid levels in blood, which may be another cause of blockage of blood vessel and an obstackle for the transfer of oxygen and nutrients needed for cellular function. Otehrwsie, this situation is often termed as atherosclerosis, a common consequence of heart attack. Otherwise, theobromine dilates blood vessels and increases urine volume. On the other hand, theophylline relaxes smooth muscles of the bronchi (Caffeine, 2010). To be mentioned that 1,3,7-trimethyl uric acid is a minor CFE metabolite (Drugbank, 2013), whose actual activities yet to be found out along with the two major theobrominederived metabolites as 1-methyl xanthine and 1-methyl-6-hydroxy xanthine. Notably, the etabolism of the metabolites has taken place prior to the urinary excretion (Verbeeck, 2008). CFE metabolites are shown in Figure 1.

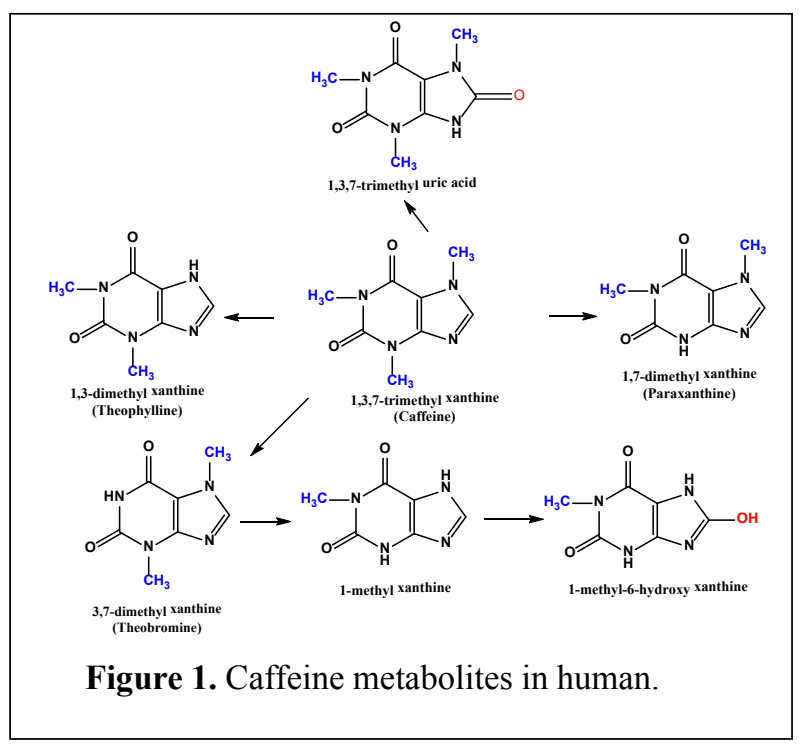

\section{Recent literature evidences}

Activities of CFE on the nervous system are vastly studied in a number of animal models. This may be due to its promising psychoactive capability. However, chronic exposure to CFE (1/3 $\mathrm{mg} / \mathrm{mL}$ ) during pre-adolescence and adolescence were found to alter the learning and memory capacities in male C57BL/6J mice (Poole et al., 2016). In a study, during a brain development stage, CFE $(0.3$ and $1.0 \mathrm{~g} / \mathrm{L})$ produced an impaired memory function in female rats (Ardais et al., 2016). On the other hand, a number of studies performed with CFE, suggesting it has some toxic effects on cardio vascular system (CVS). CFE is evident to induce a cardiomyocyte hypertrophy with the release of $\mathrm{Ca}^{2+}$ from 
the sarcoplasmic reticulum and cytosol, leading to an activation of $\mathrm{Ca}^{2+}$ /calmodulin-dependent protein kinase II (CaMKII) and p300, which in turn enhances the expression of myocyte enhancer factor-2 (MEf2) (Shi et al., 2014). Moreover, CFE (50-250 $\mu \mathrm{M})$ is also evident to increase the heart beat (Calvert et al., 2015).

CFE is evident to reduce the neonatal developmental coordination in a 5 year old child (Doyle et al., 2014) and caused a reduction in stillborn at $27 \mathrm{mg} / \mathrm{kg}$ (p.o.) with parturient sows (Superchi et al., 2016). Furthermore, CFE (50 mg/kg) exerted a sex dependent stimulatory effect in rats, where females were more active and less anxious than males (HUGHES and Hancock, 2016). A similar sex dependent effect was also demonstrated by $\mathrm{Li}$ et al. (2015) and Turgeon et al. (2016) with $120 \mathrm{mg} / \mathrm{kg} /$ day and $0.25 \mathrm{~g} / \mathrm{L}$, respectively in rats. Moreover, CFE at $100-250 \mathrm{mg} /$ day in a woman reduced the birth weight of the baby (Partosch et al., 2015), and lowered the levels of fetal blood leptin at $30-120 \mathrm{mg} / \mathrm{kg} /$ day (i.g.) in pregnant rats (Wu et al., 2015). Otherwise, in pregnant Wistar rats, CFE $(60 \mathrm{mg} / \mathrm{kg} /$ day $)$ significantly decreased scavenger receptor class B type I expression and cholesterol uptake inhibiting steroidogenesis in the fetal adrenal (Onyeso et al., 2016). It was also suggested that, high CFE consumption is associated with a greater risk of fetal development (Rodriguez et al., 2014; Ping et al., 2014), abnormal spermatogenesis (Dias et al., 2015), preterm birth (Okubo et al., 2015) and brain development (Mioranzza et al., 2014).

It also caused a dysregulation in the neuroendocrine stress response system, leading to produce psychiatric muddles including anxiety-related disorders with a treatment of $0.3 \mathrm{~g} / \mathrm{L}$ for 28 days in adolescent male Sprague-Dawley rats (O’Neill et al., 2016).

\section{Interactions:}

Moreover, CFE with 100-400 $\mathrm{mg}$ in human is demonstrated to interfere in plasma concentration $v s$ time of some drugs with the same pharmacokinetic profile (Cuesta-Gragera et al., 2015). Additionally, CFE with smoking, founded an association with schizophrenia patients $(\mathrm{n}=250)$ (Arrojo-Romero et al. 2015). Nicotine is reported to decrease the plasma half life $\left(t_{1 / 2}\right)$ of CFE by 30 to $50 \%$, while oral contraceptives can double it (Fredholm et al., 1999). On the other hand, the antidepressant, fluvoxamine can reduce the clearance of CFE more than $90 \%$ with an increase in elimination half-life greater than ten-fold; from 4.9 to 56 hours (Medscape, 2016). Moreover, CFE is also evident to produce an antagonizing effect in a time-dependent manner in ketamine/ xylazine anesthetized Sprague-Dawley rats (Kronschläger et al., 2014).

CFE has been evident to exert a stimulatory effect on luteinizing hormone (LH) secretion (Herman et al., 2015), region-dependent increase or decrease in brain activity (Xu et al., 2015), and insulin resistance (Sacramento et al., 2015). An excess level of LH may cause premature menopause, gonadal dysgenesis, turner syndrome, castration, swyer syndrome, polycystic ovary syndrome, congenital adrenal hyperplasia, testicular failure and so on. It should be also mentioned that people having difficulty to metabolize CFE may experience in chronic liver disease, including liver cirrhosis (Malenka et al., 2009; Cheston and Smith, 2013).
It is also reported that, the hormonal changes during pregnancy may slow the metabolic clearance of CFE, which may cause some complications in this category patient (Fredholm et al., 1999). A research conducted by Liguori and Robinson (2001) suggesting that the effects of CFE are affected, despite of alcohol after a cotreatment of CFE and alcohol in human.

\section{Conclusion:}

There is no doubt that, the researches on coffee and its components, especially the CFE have attracted noteworthy scientific attention in recent years due to their promising biological activities. Among the others, CFE form coffee is consumed large and popularly for its psychoactive power. Notably, CFE is cheap and readily available. From the above discussion, it is clear that, along with a number of important biological activities CFE has some toxicological impacts, especially on developmental stages, pregnant women and the fetus, high-dose mediated sleep disturbance, cardiac and reproductive complications and so forth. Therefore, more consciousness is necessary to take CFE and caffeinated products. It should be also demonstrated that, the activities of CFE are not only age, sex and patients pathophysiology-related but also it's dose-dependent. Unfortunately, we do not know about the exact amount of CFE in our coffee cups, as it depends on the sources and types of process. The above said consumer groups should restrict the caffeinated products also.

\section{Conflict of interest}

None declared.

\section{References:}

1. APA (American Psychiatric Association). Substance-Related and Addictive Disorders, (PDF). Am Psychiatr Publishing p. 1-2, 2013.

2. Arab, L., 2010. Epidemiologic evidence on coffee and cancer. Nutr. Cancer 62, 271-283.

3. Ardais, A.P., Rocha, A.S., Borges, M.F., Fioreze, G.T., Sallaberry, C., Mioranzza, S., et al., 2016. Caffeine exposure during rat brain development causes memory impairment in a sex selective manner that is offset by caffeine consumption throughout life. Behav. Brain Res. 303, 76-84.

4. Arrojo-Romero, M., Barbazán, C.A., López-Moriñigo, J.D., Ramos-Ríos, R., Gurpegui, M., Martínez-Ortega, J.M., et al., 2015. Caffeine consumption in a long-term psychiatric hospital: Tobacco smoking may explain in large part the apparent association between schizophrenia and caffeine use. Schizophrenia Res. 164, 234-241.

5. Ashton, C.H., 1987. Caffeine and health. Braz. Med. J. 295, 1293-1294.

6. Bonaventura, J., Navarro, G., Casadó-Anguera, V., Azdad, K., Rea, W., Moreno, E., Brugarolas, M., et al., 2015. Allosteric interactions between agonists and antagonists within the adenosine A2A receptor-dopamine D2 receptor heterotetramer. Proc. Natl. Acad. Sci. U.S.A. 112, E3609-3618. 
7. Caffeine., 2010. The Pharmacogenetics and Pharmacogenomics Knowledge Base. Retrieved 25 October 2010.

8. Calvert, R., Vohra, S., Ferguson, M., Wiesenfeld, R., 2015. A beating heart cell model to predict cardiotoxicity: Effects of the dietary supplement ingredients higenamine, phenylethylamine, ephedrine and caffeine. Food Chem. Toxicol. 78, 207-213.

9. Chen, L.-W., Wu, Y., Neelakantan, N., Chong, M.F.-F., Pan, A., Van Dam, R.M., 2014. Maternal caffeine intake during pregnancy is associated with risk of low birth weight: a systematic review and dose-response meta-analysis. BMC Med. 12, 174.

10. Cheston, P., Smith, L., 2013. Man died after overdosing on caffeine mints. Independent, Retrieved 13 October 2013.

11. Cuesta-Gragera, A., Navarro-Fontestad, C., Mangas-Sanjuan, V., González-Álvarez, I., García-Arieta, A., Trocóniz, I.F., et al., 2015. Validation of a semi-physiological model for caffeine in healthy subjects and cirrhotic patients. Eur. J. Pharmaceut. Sci. 73, $57-63$.

12. Dias, T.R., Alves, M.G., Bernardino, R.L., Martins, A.D., Moreira, A.C., Silva, J., et al., 2015. Dose-dependent effects of caffeine in human Sertoli cells metabolism and oxidative profile: Relevance for male fertility. Toxicol. 328, 12-20.

13. Doyle, L.W., Schmidt, B., Anderson, P.J., Davis, P.G., Moddemann, D., Grunau, R.E., et al., 2014. Caffeine for Apnea of Prematurity Trial investigators. Reduction in Developmental Coordination Disorder with Neonatal Caffeine Therapy. J. Pediatr. 165, 356-359.

14. Drugbank., 2014. Caffeine, University of Alberta. 16 September 2013. Retrieved 8 August 2014.

15. FDA., 2014. FDA Consumer Advice on Powdered Pure Caffeine. Retrieved 20 August 2014.

16. Fisone, G., Borgkvist, A., Usiello, A., 2004. Caffeine as a psychomotor stimulant: mechanism of action. Cell. Mol. Life Sci. 61, 857-872.

17. Frary, C.D., Johnson, R.K., Wang, M.Q., 2005. Food sources and intakes of caffeine in the diets of persons in the United States. J. Am. Dietetic Assoc. 105, 110-113.

18. Fredholm, B.B., Bättig, K., Holmén, J., Nehlig, A., Zvartau, E.E., 1999. Actions of caffeine in the brain with special reference to factors that contribute to its widespread use. Pharmacol. Rev. 51, 83-133.

19. Herman, A.P., Skipor, A.H.J., Krawczyńska, A., Bochenek, J., Tomaszewska-Zaremba, D., 2015. Caffeine stimulates in vitro pituitary LH secretion in lipopolysaccharide-treated ewes. Reprod. Biol. 15, 20-26.

20. Hughes, R.N., Hancock, N.J., 2016. Strain-dependent effects of acute caffeine on anxiety-related behavior in PVG/c, LongEvans and Wistar rats. Pharmacol. Biochem. Behav. 140, 51-61.

21. Iancu, I., Olmer, A., Strous, R.D., 2007. Caffeinism: History, clinical features, diagnosis, and treatment, In Smith BD, Gupta U,
Gupta BS. Caffeine and Activation Theory: Effects on Health and Behavior. CRC Press 331-344.

22. Islam, M.T., Alencar, M.V.O.B., Mata, A.M.O.F., Paz, M.F.C.J., Matos, L.A., Sousa, J.M.C., et al., 2016. Coffee: a health fuel-blot popular drinking. Int. J. Pharm. Pharmaceut. Sci. 8, 1-7.

23. Kronschläger, M., Yu, Z., Talebizadeh, N., Meyer, L.M., Söderberg, P., 2014. Topically applied caffeine induces miosis in the ketamine/xylazine anesthetized rat. Exp. Eye Res. 127, 179183.

24. Li, M., Wang, M., Guo, W., Wang, J., Sun, X., 2011. The effect of caffeine on intraocular pressure: a systematic review and metaanalysis. Graefes Arch. Clin. Exp. Ophthalmol. 249, 434-442.

25. Li, Y., Chen, L.J., Jiang, F., Yang, Y.X., Zhang, W.X.Z., Li, Z., et al., 2015. Caffeic acid improves cell viability and protects against DNA damage: involvement of reactive oxygen species and extracellular signal-regulated kinase. Braz. J. Med. Biol. Res. 48, 502-508.

26. Liguori, A., Robinson, J.H., 2001. Caffeine antagonism of alcohol-induced driving impairment. Drug Alcohol Depend. 63, 123-129.

27. Mahmud, A., Feely, J., 2015. Acute effect of caffeine on arterial stiffness and aortic pressure waveform. Hypertension 38, 227-231.

28. Malenka, R.C., Nestler, E.J., Hyman, S.E., 2009. Chapter 15: Reinforcement and Addictive Disorders, In Sydor A, Brown RY. Molecul. Neuropharmacol.: Foundation Clin. Neurosci. (2nd ed.). New York: McGraw-Hill Medical. p. 375.

29. Mayo Clinic Staff., 2012. Pregnancy Nutrition: Foods to avoid during pregnancy. Mayo Clinic. Retrieved 15 April 2012.

30. MedlinePlus., 2006. Caffeine overdose. 4 April 2006.

31. MedlinePlus., 2013. Caffeine in the diet, US National Library of Medicine. 30 April 2013.

32. Medscape., 2016. Drug Interaction: Caffeine Oral and Fluvoxamine Oral. Multi-Drug Interaction Checker. 2016.

33. Mejia, E.G., Ramirez-Mares, M.V., 2014. Impact of caffeine and coffee on our health. Trends Endocrinol. Metabol. 25, 489492.

34. Mioranzza, S., Nunes, F., Marques, D.M., Fioreze, G.T., Rocha, A.S., Botton, P.H.S., et al., 2014. Prenatal caffeine intake differently affects synaptic proteins during fetal brain development. Int. J. Develop. Neurosci. 36, 45-52.

35. O’Neill, C.E., Newsom, R.J., Stafford, J., Scott, T., Archuleta, S., Levis, S.C., et al., 2016. Adolescent caffeine consumption increases adulthood anxiety-related behavior and modifies neuroendocrine signaling. Psychoneuroendocrinol. 67, 40-50.

36. O'connor, A., 2009. Really? The claim: caffeine causes dehydration, New York Times. Retrieved 3 August 2009.

37. Okubo, H., Miyake, Y., Tanaka, K., Sasaki, S., Hirota, Y., 2015. Maternal total caffeine intake, mainly from Japanese and Chinese 
tea, during pregnancy was associated with risk of preterm birth: the Osaka Maternal and Child Health Study. Nutr. Res. 35, 309316.

38. Onyeso, G.I., Nkpaa, K.W., Omenihu, S., 2016. Coadministration of caffeine and hydromethanolic fraction of Citrullus lanatus seeds improved testicular functions in alloxaninduced diabetic male Wistar rats. Asian Pac. J. Reprod. 5, 105110.

39. Partosch, F., Mielke, H., Stahlmann, R., Gundert-Remy, U., 2015. Caffeine intake in pregnancy: Relationship between internal intake and effect on birth weight. Food Chem. Toxicol. 86, 291297.

40. Peters, J.M., 1967. Factors Affecting Caffeine Toxicity: A Review of the Literature. J. Clin. Pharmacol. J. New Drugs 7, 131141.

41. Ping, J., Wang, J.-F., Liu, L., Yan, Y.-E., Liu, F., Lei, Y.-Y., et al., 2014. Prenatal caffeine ingestion induces aberrant DNA methylation and histone acetylation of steroidogenic factor 1 and inhibits fetal adrenal steroidogenesis. Toxicol. 321, 53-61.

42. Pohanka, M., 2014. The effects of caffeine on the cholinergic system. Mini-Rev. Med. Chem. 14, 543-549.

43. Poole, R.L., Braak, D., Gould, T.J., 2016. Concentrationand age-dependent effects of chronic caffeine on contextual fear conditioning in C57BL/6J mice. Behav. Brain Res. 298, 69-77.

44. Prynne, M., 2013. Warning over caffeine sweets after father dies from overdose, Telegraph. Retrieved 13 October 2013.

45. Rodriguez, R.S., Haugen, R., Rueber, A., Huang, C.-C., 2014. Reversible neuronal and muscular toxicity of caffeine in developing vertebrates. Comp. Biochem. Physiol. Part C: Toxicol. Pharmacol. 163, 47-54.

46. Sacramento, J.F., Ribeiro, M.J., Yubero, S., Melo, B.F., Obeso,
A., Guarino, M.P., et al., 2015. Disclosing caffeine action on insulin sensitivity: Effects on rat skeletal muscle. Eur. J. Pharmaceut. Sci. 70, 107-116.

47. Sherwood, L., Kell, R., 2010. Human Physiology: From Cells to Systems (1st Canadian ed.). Nelsen p. 613-619.

48. Shi, L., Xu, H., Wei, J., Ma, X., Zhang, J., 2014. Caffeine induces cardiomyocyte hypertrophy via p300 and CaMKII pathways. Chem.-Biol. Interact. 221, 35-41.

49. Superchi, P., Saleri, R., Farina, E., Cavalli, V., Riccardi, E., Sabbioni, A., 2016. Effects of oral administration of caffeine on some physiological parameters and maternal behaviour of sows at farrowing. Res. Veterinary Sci. 105, 121-123.

50. Turgeon, S.M., Townsend, S.E., Dixon, R.S., Hickman, E.T., Lee, S.M., 2016. Chronic caffeine produces sexually dimorphic effects on amphetamine-induced behavior, anxiety and depressivelike behavior in adolescent rats. Pharmacol. Biochem. Behav. 143, 26-33.

51. Verbeeck, R.K., 2008. Pharmacokinetics and dosage adjustment in patients with hepatic dysfunction. Eur. J. Clin. Pharmacol. 64, 1147-1161.

52. Vilarim, M.M., Rocha Araujo, D.M., Nardi, A.E., 2011. Caffeine challenge test and panic disorder: A systematic literature review. Expert. Rev. Neurotherapeut. 11, 1185-1195.

53. Wolf, A., Bray, G.A., Popkin, B.M., 2008. A short history of beverages and how our body treats them. Obesity Rev. 9, 151-164.

54. Wu, Y.-M., Luo, H.-W., Kou, H., Wen, Y.-X., Shen, L., Pei, L.G., et al., 2015. Prenatal caffeine exposure induced a lower level of fetal blood leptin mainly via placental mechanism. Toxicol. Appl. Pharmacol. 289, 109-116.

55. Xu, F., Liu, P., Pekar, J.J., Lu, H., 2015. Does acute caffeine ingestion alter brain metabolism in young adults? NeuroImage 110, 39-47. doi: 10.1016/j.neuroimage.2015.01.046. 